\title{
Geochemical characteristics of condensates in the Xihu Sag, East China Sea Basin
}

\author{
JIAYANG Li $^{1}$ ZHIHUAN ZHANG ${ }^{1 *}$ \\ ${ }^{1}$ State Key Laboratory of Petroleum Resources and \\ Prospecting, College of Geosciences, China University of \\ Petroleum, Beijing 102249, China \\ (*correspondence:zhangzh3996@vip.163.com)
}

The Xihu Sag is the prime gas and condensate-producing region in the East China Sea Basin. However, compared with the gas, the origin and formation mechanism of the condensates have received less attention. This study aims to carry out comprehensive research on the geochemical characteristics of the condensates, which laid the foundation for the research on the origin of condensates.

The condensates are characterized by low density, low wax, low API gravity, low sulfur content, low freezing point, low content of resin and asphaltenes, and high content of the saturated hydrocarbon fraction, i.e., the characteristic of "six low and one high". The $n$-alkanes of condensates ranging from $C_{11}$ to $C_{35}$ are present and their profiles fall into two patterns (i.e., unimodal and bimodal distribution without oddto-even predominance). The $\mathrm{Pr} / \mathrm{Ph}$ ratios of most condensates are higher than 4.0, indicating oxic depositional environment. $\mathrm{C}_{27}-\mathrm{C}_{30}$ hopanes are the dominant compounds, and homohopanes decrease consistently from $\mathrm{C}_{31}$ to $\mathrm{C}_{35}$ in most of the condensates. $\mathrm{C}_{27} 17 \alpha(\mathrm{H})-22,29,30$-trisnorhopane (Tm) is significantly more abundant than $\mathrm{C}_{27} 18 \alpha(\mathrm{H})-22,29,30$ trisnorneohopane $(\mathrm{Ts})$, and $\mathrm{Ts} /(\mathrm{Ts}+\mathrm{Tm})$ ratios are generally lower than 0.3 . The gammacerane $/ \mathrm{C}_{30} \quad \alpha \beta$ hopane (gammacerane index) ratio of the condensates is relatively low $(<0.1)$. The condensates contain high content of diterpenoids, including norisopimarane, isopimarane and phyllocladane, and relatively lower abundance of sesquiterpenoids, such as 4,4,8,8,9-pentamethyldecalin drimane and homodrimane. Generally, regular steranes are moderately dominated by $\mathrm{C}_{29}$ regular steranes. Therefore, the condensates originate from the source rocks deposited in the environment with low palaeosalinity and a large contribution from land plants.

The $\mathrm{C}_{29} \quad \alpha \alpha \alpha \quad 20 \mathrm{~S} /(20 \mathrm{~S}+20 \mathrm{R})$ sterane ratios, $\mathrm{C}_{29}$ $\alpha \beta \beta /(\alpha \beta \beta+\alpha \alpha \alpha)$ sterane ratios, $C_{31} 22 \mathrm{~S} /(22 \mathrm{~S}+22 \mathrm{R})$ homohopane ratios have reached equilibrium, and the CPI and OEP values keep close to 1.0, suggesting a high thermal maturity of the condensates. 